Article

\title{
Profiling and Structural Characterization of High Neu5Gc or Sulfate-Containing $O$-glycans from Hyla Rabbit Intestinal Mucin
}

\author{
Qianyun Fu ${ }^{1}$, Guoyun $\mathrm{Li}^{1,2, *}$, Chen Wang ${ }^{1}$, Ya Wang ${ }^{1}$, Qinying $\mathrm{Li}^{1}{ }^{1}$, Jiejie Hao ${ }^{1,2}$ and \\ Guangli Yu ${ }^{1,2} \mathbb{D}$ \\ 1 Key Laboratory of Marine Drugs, Ministry of Education, Shandong Provincial Key Laboratory of \\ Glycoscience and Glycotechnology, School of Medicine and Pharmacy, Ocean University of China, \\ Qingdao 266003, China; fqy15764210034@163.com (Q.F.); wangchen_echo@163.com (C.W.); \\ yawangouc@163.com (Y.W.); liqinying2010@163.com (Q.L.); 2009haojie@ouc.edu.cn (J.H.); \\ glyu@ouc.edu.cn (G.Y.) \\ 2 Laboratory for Marine Drugs and Bioproducts, Qingdao National Laboratory for Marine Science and \\ Technology, Qingdao 266003, China \\ * Correspondence: liguoyun@ouc.edu.cn; Tel.: +86-532-8203-1615
}

Received: 4 February 2019; Accepted: 4 April 2019; Published: 7 April 2019

\begin{abstract}
Intestinal mucins constitute the major component of the mucus covering the epithelium of the gastrointestinal tract, thereby forming a barrier against microbial colonization. Rabbits are bred in large numbers worldwide, with little known about intestinal $O$-glycosylation despite this insight being crucial to the understanding of host-pathogen interactions. In the present study, a major mucin-type glycopeptide (RIF6) of hyla rabbit intestine was isolated and the O-glycans were extensively characterized based on liquid chromatography-tandem mass spectrometry (LC-MS/MS) combined with bioinformatics approaches. Thirty-three $O$-glycans were identified, and most of them were sulfated or sialylated glycans. It was worth noting that Neu5Gc-containing structures within sialylated $O$-glycans accounted for $91 \%$, which were extremely different from that of other species including humans, mice, chickens, etc. Sulfated glycans accounted for $58 \%$, unique disufated and sulfated-sialylated glycans were also detected in rabbit intestinal mucin. These structural characterization reflected species diversity and may provide deeper insights into explaining the adaptability of hyla rabbit to the environment.
\end{abstract}

Keywords: Hyla rabbit intestinal mucin; O-glycan; Neu5Gc; structural characterization

\section{Introduction}

The intestine, an important part of the digestive system, is comprised of a complex organization of epithelium, immune cells, and resident microbiota [1]. The intestinal epithelium is covered by a mucus layer, which together with other substances forms the front line of defense to prevent microbial colonization and avoid erosion of the underlying epithelia [2].

Intestinal mucins, the major components of the mucus layer in intestine, are extensively O-glycosylated proteins that comprise up to $80 \%$ of the mucin by weight. These mucins play an essential role in protecting the underlying epithelium from chemical and mechanical stresses. Additionally, the mucin provides binding sites for pathogenic microbes, as well as serves as an abundant potential carbon source for resident microflora [3]. Several studies have indicated that alterations in mucin structure can be utilized to distinguish different species or certain diseases, such as Crohn's disease, cystic fibrosis, or cancer [4-11]. Furthermore, O-glycan structural diversity in 
different species can contribute to the selection of microbial communities along and across the intestinal tract $[12,13]$.

Rabbits are herbivores that are bred in large volumes worldwide. Infectious diseases of the digestive system currently cause up to $60 \%$ mortality of rabbit, which greatly influence rabbit farming. These enteric diseases are caused by the presence of the pathogen [14]. Previous studies have indicated that endogenous glycans, such as $\mathrm{O}$-glycans, exert a great effect on intestinal health by maintaining the balance of microbial community [15]. However, despite the intestine being important to the overall health, little is known regarding unique intestinal $O$-glycosylation and how it impacts host-pathogen interactions in rabbits. Therefore, rabbit intestinal mucin-type glycopeptides were obtained and the $\mathrm{O}$-glycans were characterized using LC-MS ${ }^{\mathrm{n}}$ and various bioinformatics approaches in glycomics.

\section{Results}

\subsection{Purification and Chemical Analysis of Hyla Rabbit Intestinal Mucins}

Papain was used to obtain the mucin-type peptides from the rabbit intestines. Following purification by using QFF chromatography, four glycopeptide fractions (RIF4, RIF6, RIF8, and RIF10) were acquired. According to the monosaccharide composition analysis (Supplementary Information, Table S1), RIF6 was predominantly composed of Gal, GlcNAc, GalNAc and Sialic acid (Supplementary Information, Figure S1), which was consistent with mucin character, and thus was further characterized for the O-glycan studies. Whereas minor content of GalNAc and Gal in RIF4 ruled out its possibility of being O-glycans, RIF8 and RIF10 were glycosaminoglycans according to their monosaccharide composition.

\subsection{Structural Analysis of O-glycan by LC-MS/MS}

The $O$-glycans were released by using the reductive $\beta$-elimination method, and all $O$-glycans would be existed in its alditol form. The profiling of the $O$-glycans was performed on a porous graphitized carbon column separation and online LC-MS ${ }^{\mathrm{n}}$ analysis technique [16]. All data obtained from LC-MS ${ }^{n}$ were analyzed with bioinformatics softwares. Collision-induced dissociation (CID), a fragmentation technique, was adopted to characterize the fine structures of $O$-glycan. The parent ions derived from the full MS were labeled as various fragments which could then be utilized to determine the core type, specific linkage mode, and the positions of fucose or sialic acid [17-21]. The naming rules for the fragment ions were based on previously described nomenclature [22], with $A_{i}, B_{i}$, and $C_{i}$ representing fragment ions containing non-reducing ends, while $X_{j}, Y_{j}$, and $Z_{j}$ representing fragment ions containing reducing ends. Additionally, the subscript $\alpha$ is used to represent longer branches in the $O$-glycan chain, while the subscript $\beta$ represents shorter ones.

\subsubsection{LC-MS/MS Revealed Overall Structural Characteristics}

O-Glycans from RIF6 were detected as singly and doubly charged ions in negative-ion mode (Table 1). Overall, $33 \mathrm{O}$-glycans were characterized, containing six sulfated or Neu5Gc-containing structures unique to the rabbits $(\mathrm{m} / \mathrm{z} 747,837,982,488,529,836)$. The $O$-glycans were $2-6$ residues long, and most were sulfated or sialylated. The distribution of $O$-glycans from RIF6 was $25.46 \%$ neutral, $10.40 \%$ sialylated, $57.7 \%$ sulfated, $16.92 \%$ fucosylated and $4.87 \%$ sulfated-sialylated glycans (Figure 1 ). It is worth noting that the five most abundant structures $(\mathrm{m} / \mathrm{z} 667,425,464,733$ and 732$)$ accounted to $72.22 \%$ of total content. Most of these five structures were sialylated or sulfated core 3 . 
Table 1. The assigned O-glycans of RIF6 based on ESI-CID-MS/MS.

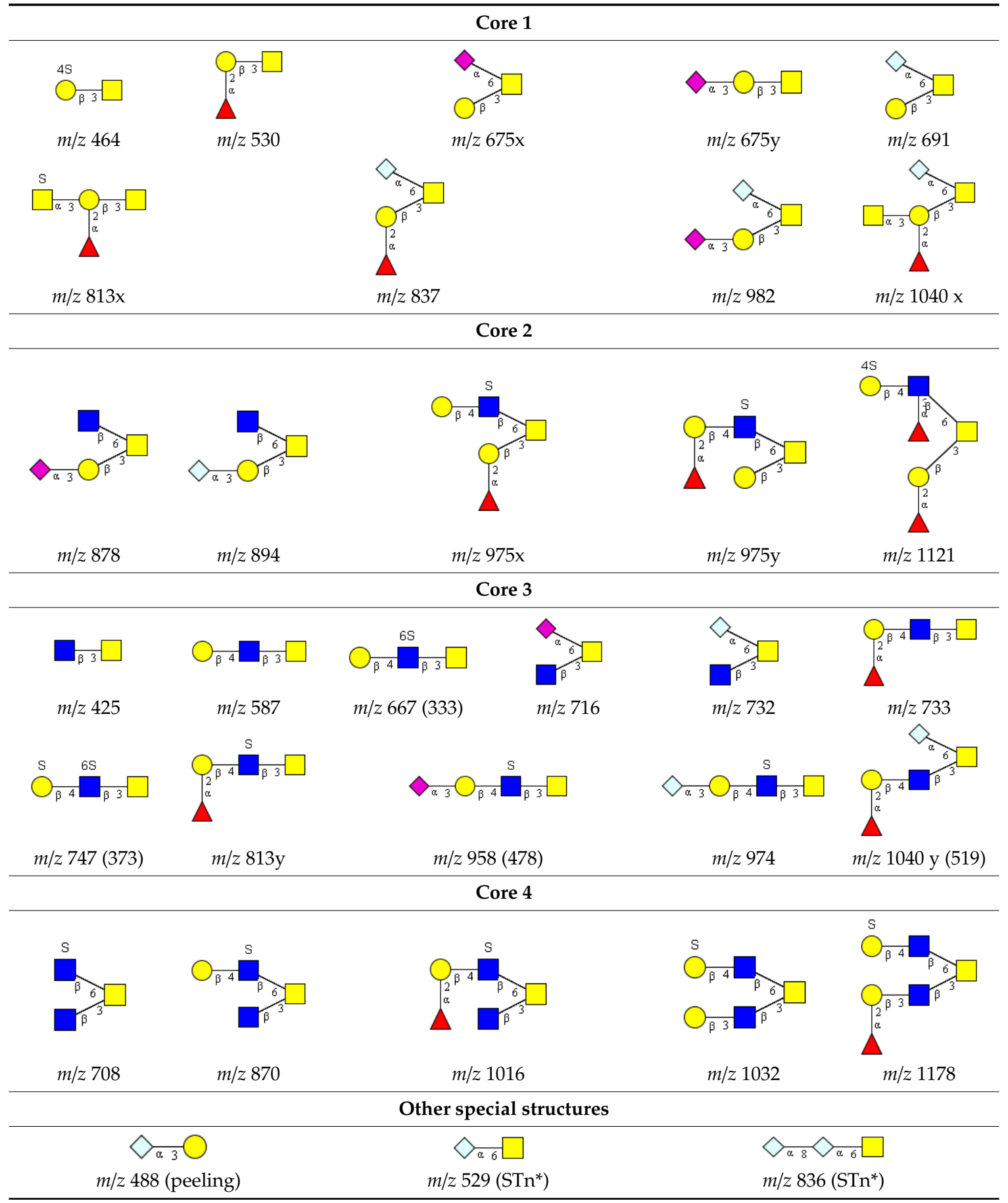

'STn': Sialyl-Tn antigen. Monosaccharide symbols are based on the Consortium for Functional Glycomics (CFG) nomenclature: blue square, GlcNAc; yellow square, GalNAc; yellow circle, Gal; purple diamond, Neu5Ac; write diamond, Neu5Gc; red triangle, Fuc. 
(a)

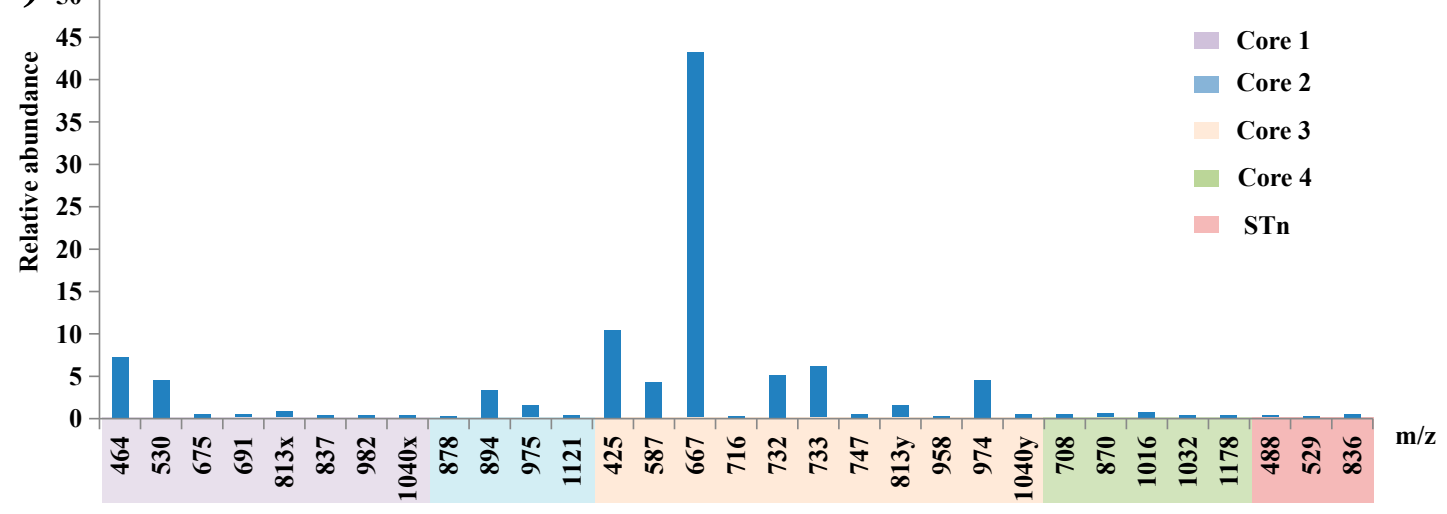

(b)
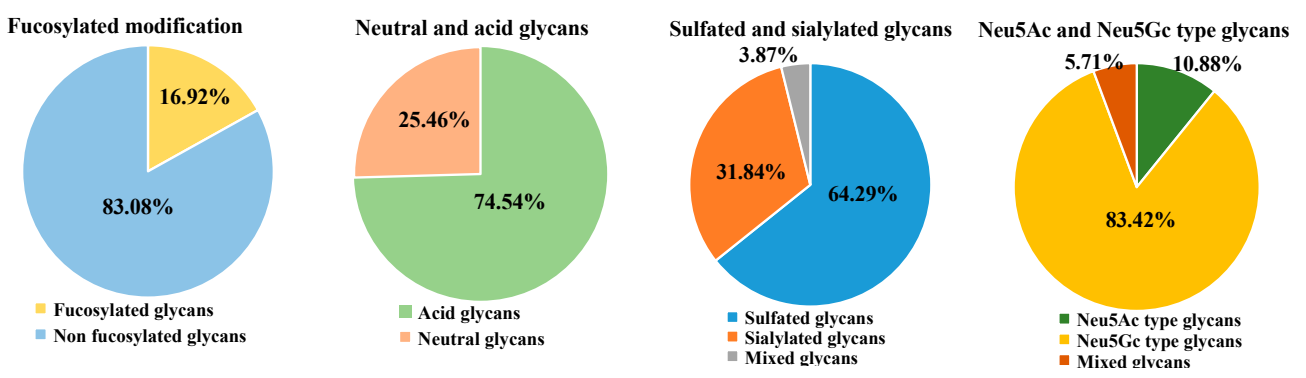

Figure 1. Composition and content of O-glycans. (a) Quantitative graph of 33 kinds of $O$-glycans existed in rabbit intestines. (b) Percentage of different types of $O$-glycans with various modifications.

\subsubsection{Core 3 Extended with Type II LacNAc Is the Main O-glycan Type}

Core structures can be easily identified from CID spectra by the loss of a moiety from the pseudomolecular ion $[16,20,23]$. Core 3 structure represented the largest proportion of glycans $(75.22 \%)$ based on the integral areas of the MS analysis. The B type ion $(\mathrm{m} / \mathrm{z} 202)$ in Figure $2 \mathbf{a}$ and $Z_{2}(\mathrm{~m} / \mathrm{z} 407)$ in Figure $2 \mathrm{f}$ indicate the presence of core 3 type structures. Furthermore, core 1 can be also detected based on different $Z_{1 \beta}$ ions formed by the loss of the Gal (Figure $\left.2 b\right)$. Two structures $(m / z 813,1040)$ containing both core 1 and core 3 isomers are also detected. The $m / z 614$ and $m / z 507$ fragments (Figure 2c,d) indicate the presence of cores 2 and 4. In Figure 2f,e, the ${ }^{0,2} \mathrm{~A}_{2} /{ }^{0,2} \mathrm{~A}_{2 \alpha}-\mathrm{H}_{2} \mathrm{O}$ fragment ion at $m / z 280, m / z 343$ indicates the presence of a type II chain. The majority of identified glycans were type II lactosamine structures (15 of 33), accounting for $64.59 \%$ according to integral area. Among these structures, core 3 structures were the main portion elongated with a type II lactosamine. 
(a)

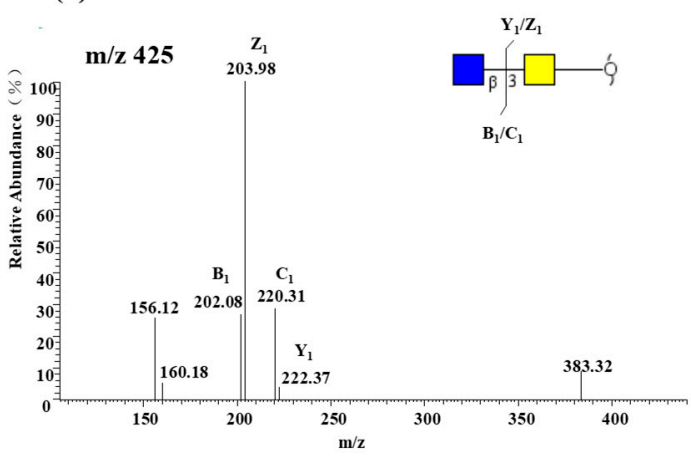

(c)

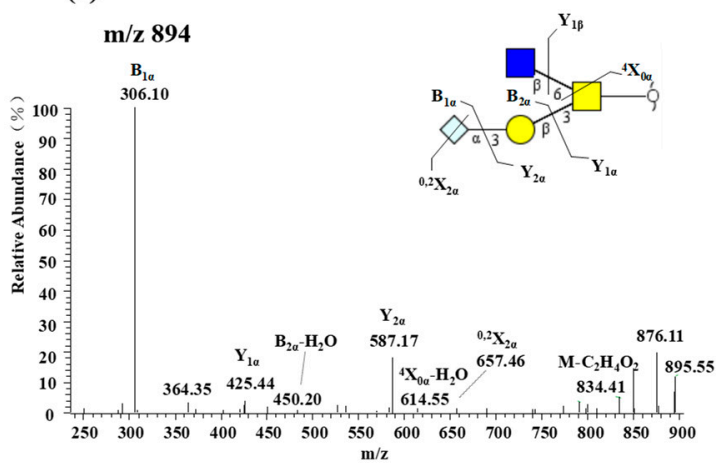

(e)

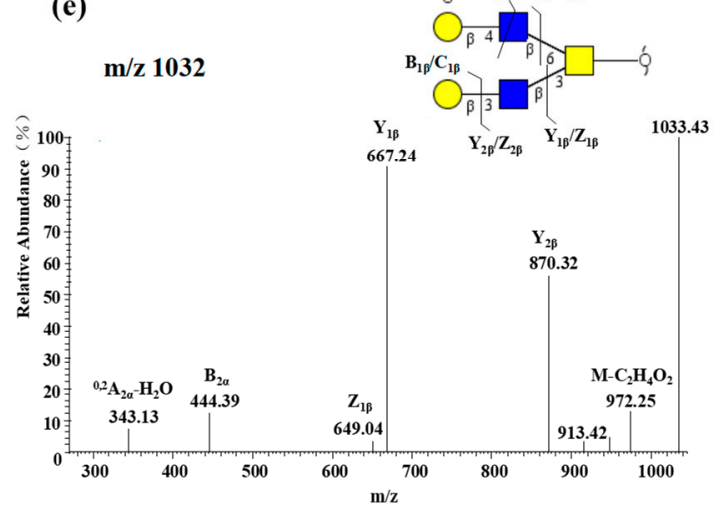

(b)

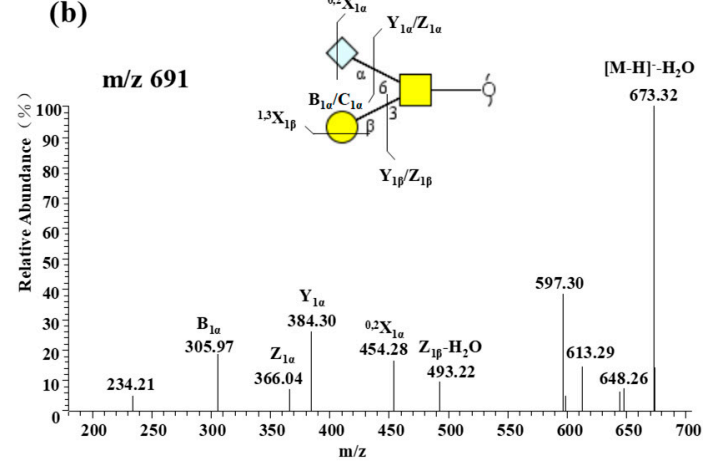

(d)
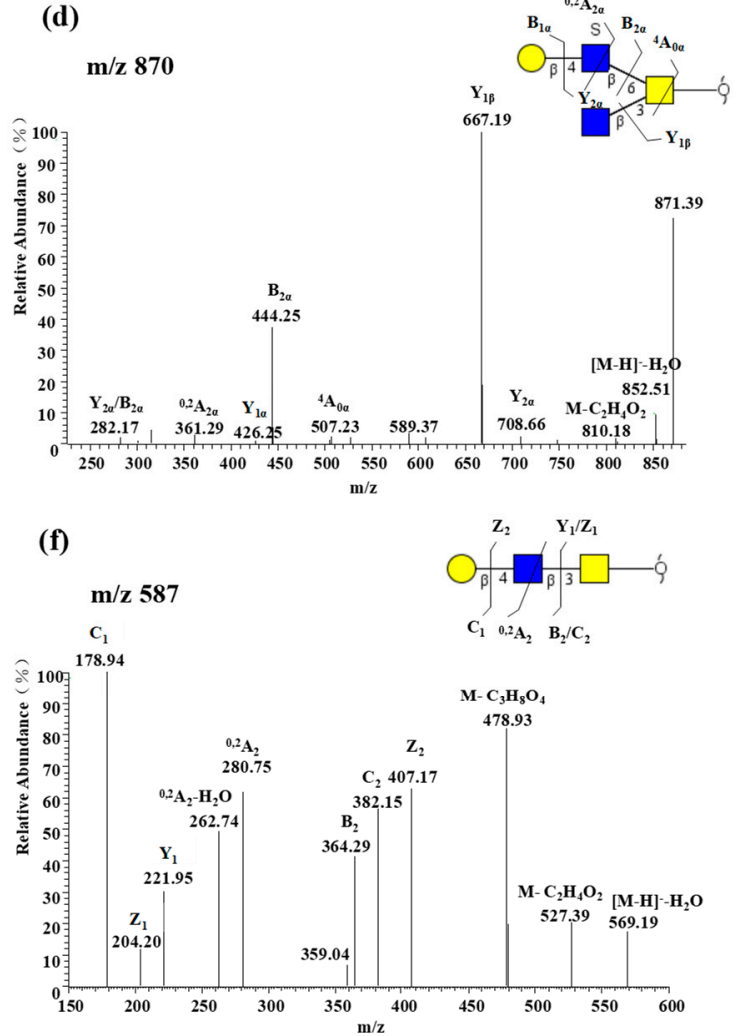

Figure 2. MS/MS spectra in the negative ion mode and proposed fragmentation of O-glycan with different core types and two isomeric oligosaccharides: (a) core 3 oligosaccharide at $\mathrm{m} / \mathrm{z} 425$

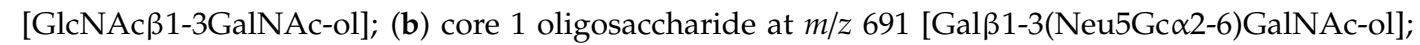
(c) core 2 oligosaccharide at $m / z$ 894 [Neu5Gc $\alpha 2-3 G a l \beta 1-3(G l c N A c \beta 1-6) G a l N A c-o l] ;$ (d) core 4 oligosaccharide at $m / z 870$ [Gal $\beta 1-4\left(\mathrm{SO}_{3}{ }^{-}\right)$GlcNAc $\beta 1-6(\mathrm{GlcNAc} \beta 1-3)$ GalNAc-ol]; (e) oligosaccharide with both Galß1-3 linked and Galß1-4 linked to a GlcNAc residue; (f) oligosaccharide with a Gal $\beta 1-4$ linked to a GlcNAc residue.

\subsubsection{Notable Feature of High Neu5Gc-containing O-glycans}

O-glycans from RIF6 were heavily sialylated. Almost half of the identified O-glycans (16 of 33) were sialylated with $18.18 \%$ sialylated core $1,6.06 \%$ sialylated core $2,15.15 \%$ sialylated core 3 and $9.09 \%$ sialylated Tn antigen. Two types of sialic acid, Neu5Ac (6 of 33) and Neu5Gc (11 of 33), were detected. Herein, the B ion at m/z 290 in MS/MS spectra (Figure 3a,b) corresponds to a Neu5Ac residue and the ion at $m / z 306$ (Figure 2b,c) corresponds to a Neu5Gc residue. One structure at $m / z 982$ in the MS/MS spectra (Supplementary Information, Figure S3) was also found containing Neu5Gc and Neu5Ac. Among these sialylated O-glycans, the Neu5Gc-containing glycans represented the most 
notable content and constituted 91\%. The linkages included $\alpha 2-3$ linkages to Gal, $\alpha 2-6$ linkages to GalNAc-ol, or an $\alpha 2-8$ linkage to di- or polysialyl motifs. The fragment ion at $m / z 469$ (Figure 3b) serves as a diagnostic ion for a Neu5Ac residue directly linked to Gal via an $\alpha 2-3$ linkage. In addition to these ions, the fragment ion at $m / z 348$ (Figure 3c) is annotated as ross-ring cleavage of ${ }^{4} \mathrm{~A}_{0}-\mathrm{H}_{2} \mathrm{O}$, indicating a sialic acid linkage to the core GalNAc-ol. The structure at $m / z 675$ contained two isomers with Neu5Ac linking to Gal (Supplementary Information, Figure S3) or core GalNAc-ol (Figure 3d). Seven of 16 sialylated structures contained $\alpha 2-6$ and six of 16 contained $\alpha 2-3$ linkages. Notably, 2 Neu5Gc-containing structures $(m / z 894,974)$ accounted for $56 \%$ according to the integral area.
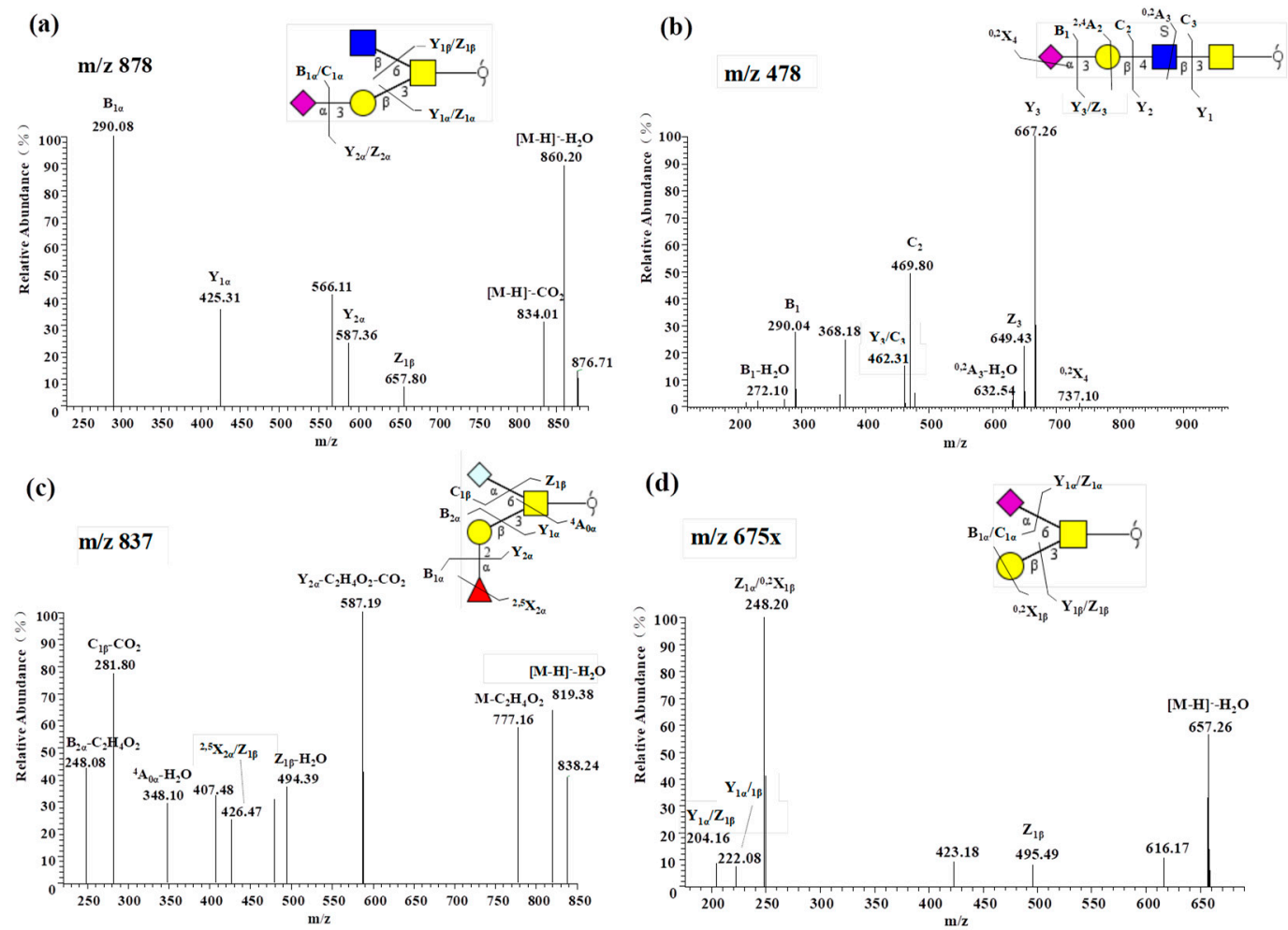

Figure 3. MS/MS spectra of sialylated oligosaccharides recorded in the negative ion mode: (a) and (b) oligosaccharide with a Neu5Ac $\alpha 2-3$ linked to a Gal residue; (c) oligosaccharide with a Neu5Gc $\alpha 2-6$ linked to a GalNAc-ol; (d) oligosaccharide with a Neu5Ac $\alpha 2-6$ linked to a GalNAc-ol.

\subsubsection{Characterization of Highly Sulfated O-glycans}

O-glycans of RIF6 were highly sulfated with 15 of 33 O-glycans being identified. Among these sulfated glycans, most were monosulfated (14 of 15), with minor trace of disulfated glycans (Figure 4c). The content of sulfated glycans was up to $58 \%$ with one particular structure $(\mathrm{m} / \mathrm{z} 667)$ accounting for $43 \%$. The location of sulfate was found on Gal, GlcNAc or GalNAc. The presence of the $m / z$ 241 (Figure $4 \mathrm{a}$ ) or $\mathrm{m} / \mathrm{z} 282$ (Figure $4 \mathrm{~b}$ ) ions indicates that the sulfate groups are located on a Hex or HexNAc. The C-4 position linked to a Gal and the C-6 to GlcNAc were detected. A sulfated linkage to a monosaccharide residue can be distinguished by various specific ring cleavages [17]. Herein, the ${ }^{2,4} \mathrm{~A}$ and ${ }^{3,5} \mathrm{~A}$ fragment ions (Figure $4 \mathrm{a}$ ) indicate a substitution of $\mathrm{C}-4$ linkage. The fragment ion generated via ${ }^{0,4} \mathrm{~A}$-type and ${ }^{0,2} \mathrm{~A}$-type cleavage (Figure $4 \mathrm{~d}$ ) can serve as the diagnostic ion for the C-6 sulfate substitution of HexNAc. 
(a)

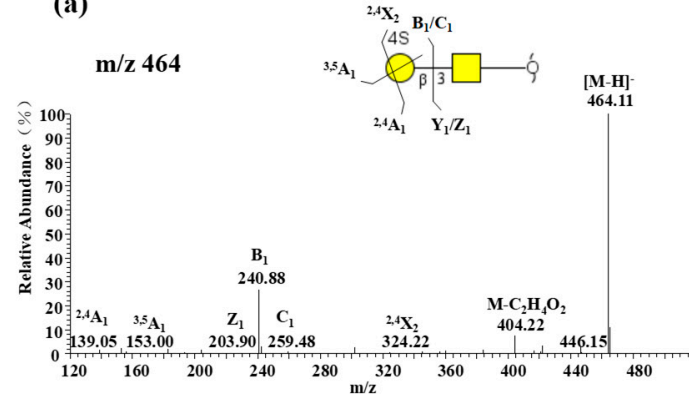

(c)

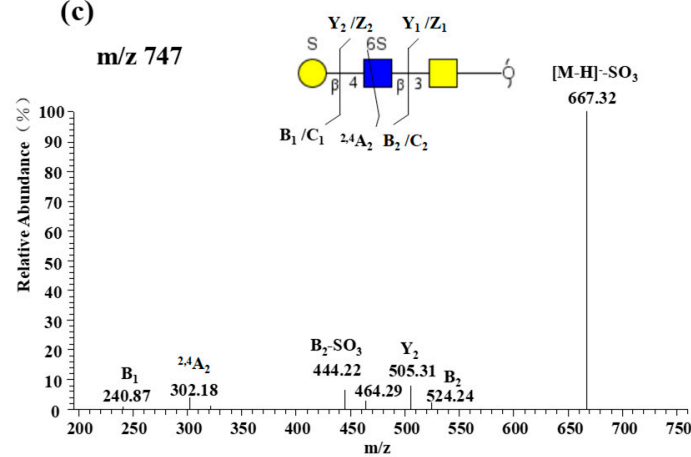

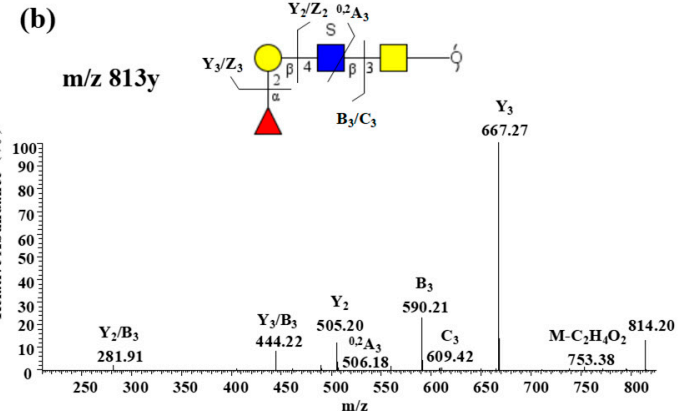

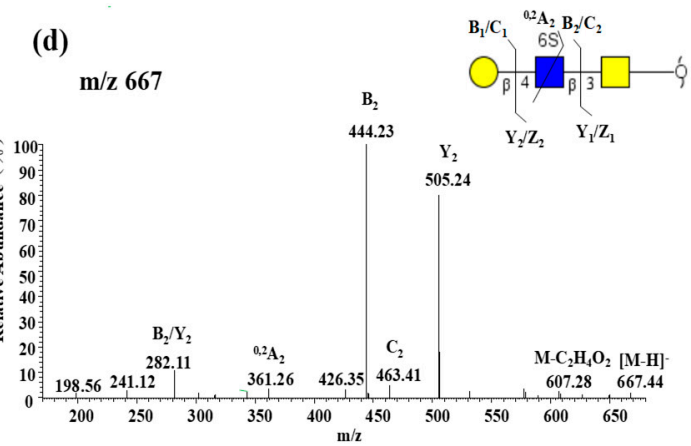

Figure 4. MS/MS spectra of different sulfated oligosaccharides recorded in the negative ion mode: (a) $\left(\mathrm{SO}_{3}{ }^{-}\right) 4 \mathrm{Gal} \beta 1-3 \mathrm{GalNAc}-\mathrm{ol}$; (b) Fuc $\alpha 1-2 \mathrm{Gal} \beta 1-4\left(\mathrm{SO}_{3}{ }^{-}\right) \mathrm{GlcNAc} \beta 1-3 \mathrm{GalNAc}-\mathrm{ol}$; (c) $\left(\mathrm{SO}_{3}{ }^{-}\right) \mathrm{Gal} \beta 1-4$ $\left(\mathrm{SO}_{3}{ }^{-}\right) 6 \mathrm{GlcNAc} \beta 1-3 \mathrm{GalNAc}-\mathrm{ol}$; (d) Gal $\beta 1-4\left(\mathrm{SO}_{3}{ }^{-}\right) 6 \mathrm{GlcNAc} \beta 1-3 \mathrm{GalNAc}-\mathrm{ol}$.

\subsubsection{Presence of $\alpha 1-2$ Fucose-containing O-glycans}

In mucin-type O-glycans, the location of fucose can, to a certain extent, determine the type of epitope [20]. In this study, 12 of 33 structures contained fucose residues, mainly with an $\alpha 1-2$ fucose linkage to Gal to form several antigens. Among these antigens, the blood group H epitopes (10 of 33) were predominated, along with Lewis ${ }^{x}$ ( 1 of 33 ) and group A ( 2 of 33). The total level of fucosylated glycans constituted $17 \%$ of all glycans base on MS intensities (Figure 1). The content of $\mathrm{H}$ epitopes was up to over $86 \%$ within glycans with fucose residues. Non-reducing end $\mathrm{H}$ antigen fragments are always accompanied by the $\mathrm{B}-\mathrm{C}_{2} \mathrm{H}_{4} \mathrm{O}_{2}$ ions of $m / z 247$ (Figure $5 \mathrm{a}$ ), which is characteristic of a C-2 substituted Gal. In Figure $5 b$, the $Y_{2 \beta}(m / z 975)$ and $Y_{1 \beta}(m / z$ 813) cleavage ions indicate that an $\alpha 1-2$ fucose linkage to Gal was present.
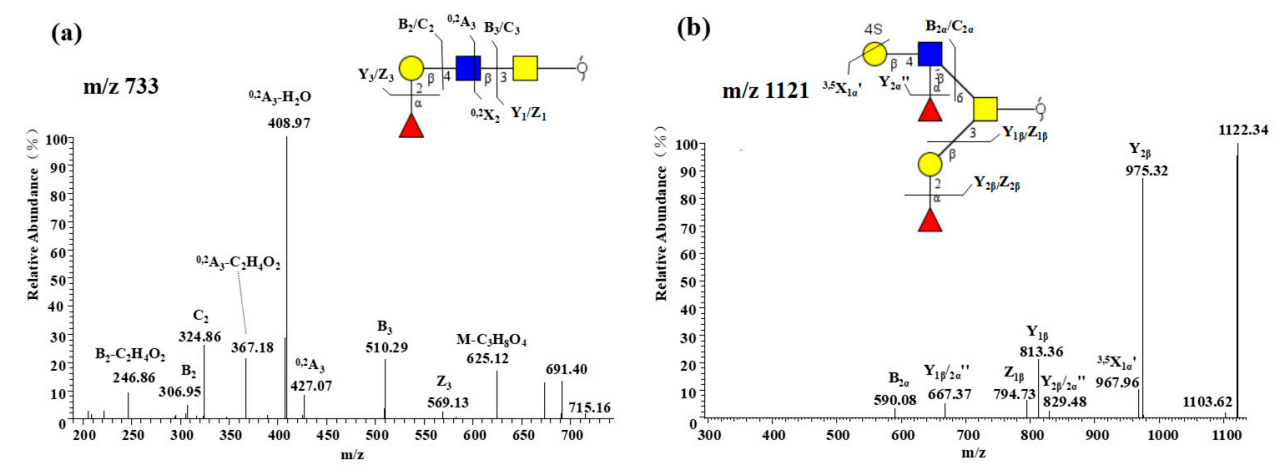

Figure 5. MS/MS spectra of two fucosylated oligosaccharides recorded in the negative ion mode: (a) oligosaccharide with $\alpha 1-2$ fucose linkage to Gal residue; (b) oligosaccharide with $\alpha 1-2$ fucose linkage to Gal residue and $\alpha 1-3$ fucose linkage to GlcNAc residue. 


\section{Discussion}

O-Glycans on intestinal mucin are of great significance in protecting against harmful substances, maintaining balance of beneficial microbial community and helping rabbits to keep healthy. In this study, $\mathrm{O}$-glycans from rabbit intestinal mucin-type glycopeptides were characterized, rendering this the first elaborate $O$-glycan profiling of hyla rabbit mucins. $33 \mathrm{O}$-glycans were characterized, and most were heavily sialylated or sulfated. These identified $O$-glycans showed great similarity (17 of 33) to that of pigs, which are also domestic mammal as rabbits (Supplementary Information, Table S2). Additionally, one disulfated $(m / z 747)$ and five Neu5Gc-containing structures $(m / z 488,529,836,837,982)$ were unique to the rabbits. This reflects the joint action of genetic inheritance and environmental selectivity.

Cores 1, 2, 3, 4 and several Tn antigen were detected. Of these glycans, core 3 was the most abundant core type. This structure has showed an important role in reducing intestinal permeability and levels of bacteria within mucosa, thus promoting mucosal barrier function [24]. These findings are similar to previous studies in human [19] and chicken [25] intestines. However, it shows differences in other species, such as the porcine colon containing predominantly core 4 [26], mouse intestines mostly comprising core 2 [27], and fish intestine mostly consisting of core 5 [28]. Particularly, $m / z$ 667, a sulfated core 3 structure, made up $43.19 \%$ of total glycans, which extensively existed in the intestines of humans and chickens with same core structure, but displayed in mouse and pig intestines with different isomers. Species-specific core type glycan expression reflects differences in needs of intestinal microorganism, encountered environmental challenges, and species diversity.

Abundant Neu5Gc-containing glycans was the most unique feature in rabbit intestines. The identified Neu5Gc-containing structures were never found in intestines of humans or chickens whereas displayed 3 same glycans with pigs (Supplementary Information, Table S2). Notably, the content of Neu5Gc-containing glycans within sialylated O-glycans accounted for $91 \%$, which was extremely higher than that in other species' intestines. The most abundant three Neu5Gc-containing glycans $(\mathrm{m} / \mathrm{z} 732,974,894)$ were only detected a small amount $(1.8 \%)$ in pig intestines, but reached up to $13.08 \%$ of total content in the rabbit intestines. Interestingly, the content of Neu5Gc $\alpha 2-3 \mathrm{Gal}$ structures in rabbit intestines accounted for $56 \%$ among sialylated glycans, even though only two structures $(m / z$ 894, 974) were characterized. As prominent outermost carbohydrates on mucins, sialic acids play important regulatory and protective roles in cell biology [29]. Unique content of Neu5Gc may also alter the functions of endogenous receptors for sialic acids in the immune system [30]. Besides, many major pathogens gain access to their mammalian hosts by binding to certain sialic acids types or linkages in the surface of glycan chains. Previous studies have showed E. coli K99, a pathogen that has a strong preference for Neu5Gc, can cause serious diarrheal diseases in farm animals like cows and pigs [30]. Human influenza A virus preferentially recognize SA $\alpha 2-6 \mathrm{Gal}$ linkage, whereas most animals are infected by $\alpha 2,3$-specific influenza A virus [31]. Another research revealed recognition of Neu5Gc $\alpha 2-3 \mathrm{Gal}$ structure is related to the efficient replication of influenza viruses in duck intestines [32]. Therefore, abundant Neu5Gc-containing glycans may make rabbits be susceptible to diseases such as influenza viruses or diarrheal. Additionally, rabbits share less similar microorganisms composition with other species which are high in Neu5Ac, thus conferring protection for both of species from animal pathogens and diseases. For example, rabbits may be resistant to parasite infection which is in specificity toward Neu5Ac in rat intestines [33]. This parallels the loss of Neu5Gc in humans and chickens, which are the only two animals that lack the cytidine monophosphate (CMP)- $N$-acetylneuraminic acid hydroxylase (CMAH) gene required to synthesize Neu5Gc [34,35]. The absence of Neu5Gc makes humans and chickens be not prone to infections by viruses and bacteria which recognize Neu5Gc only and can live close to rabbits [36]. Rabbit intestines have been used as food source in many Asian countries, however, some studies have revealed that much intake of Neu5Gc-containing food may contribute to a higher cancer frequency and other dietary associated diseases in humans [37]. Thus, the higher rabbit intestinal Neu5Gc levels may also provide dietary references to prevent cancer or other related diseases in humans. 
The extent of sulfation is further emphasized as another unique feature when compared with other results from intestines in human, pig and fish (Supplementary Information, Table S2). Fifteen out of 33 indentified $O$-glycans were sulfated structures in rabbit intestines. It is to be noted that the content of these sulfated glycans accounted for $58 \%$. And most were monosulfated, which was consistent with the previous human mucin studies [38]. Compared with other species, one disulfated glycan $(\mathrm{m} / \mathrm{z} 747)$ and two sulfated-sialylated glycans $(\mathrm{m} / \mathrm{z} 958,974)$ were also detected as unique structural features in rabbit intestines (Supplementary Information, Table S2). Sulfated structures in rabbit intestines were extended cores 1, 2, 3, 4, which were different from structures in other species, such as the absence of sulfated core 4 glycans in humans, even the absence of sulfated structures verified in fish intestines (Supplementary Information, Table S2). As was observed in rabbits, many species have extensively sulfated intestinal mucin $O$-glycans $[25,27,39]$. Previous studies showed that core $1-4$ and 6 serve as potential substrates for sulphotransferases (STs). Two main mucin STs, GlcNAc6ST and Gal3ST, transfer sulphate from 3-phosphoadenosine 5-phosphosulphate (PAPS) to the 6-position of GlcNAc and the 3-position of Gal, respectively [40]. The expression of GlcNAc6ST and Gal3ST differ in different species. For instance, the GlcNAc6ST-2 transferase has been shown to be a major sulfation enzyme in the murine colon, and this enzyme is responsible for the predominant GlcNAc-6-O-sulfation in mouse colonic mucins [41]. The GlcNAc6ST-3 was mainly expressed in human intestines [42]. Additionally, Gal3ST-2 transferase was upregulated in the pathogen resistant chickens [25]. These expression changes of STs may account for various sulfated modification in intestinal mucins of different species. In another study, infected pig colons had lower levels of sulfated structures when compared with non-infected porcine [26]. Abundant charged structures (sulfated, sialylated and sulfated-sialylated) in rabbit intestines confer acidic properties which can change epithelial cell interactions or even modulate bacterial interactions by hindering bacterial degradation as previous studies have revealed [43,44].

Terminal fucosylated epitopes have been reported to act as binding sites for various pathogens. Campylobactor jejuni, the most common source of food poisoning and a common cause of death [45,46], is a bacterium usually present in the intestinal tract. Previous study reported the ABO blood group antigens can be utilized by C. jejuni as adhesion receptors [47]. The blood group H epitopes (10 of 33) may act as bacterial receptors within the rabbit intestine. However, this effect could be modulated when these structures carry charged residues, such as sialic acid or sulfate [25]. Large portions of the antigenic epitopes were modified by Neu5Gc or the addition of sulfate (Table 1), which may balance the relationship between intestines and bacteria, thus promoting the health of rabbits.

The analysis of rabbit intestinal mucin-type glycans provides a platform for deeper understanding on how structural differences in glycosylation could explain the adaptability to the environment. The structural features of rabbit intestines, especially the presence of highly sialylated and sulfated modification, may provide unique mucus environments to help specialized microflora to live and protect mucus from degradation. Notable and abundant content of Neu5Gc-containing glycans in rabbit intestines explains susceptibility or resistance to certain pathogens or diseases for rabbits and also provides dietary references for humans.

\section{Materials and Methods}

\subsection{Materials and Chemicals}

Hyla rabbit intestines were provided by Kangda Food Co., Ltd. (Qingdao, China). Papain was purchased from Amresco (Solon, OH, USA). Q-Sepharose Fast Flow resin was procured from GE Healthcare (Uppsala, Sweden). Mannose (Man), $N$-acetylglucosamine (GlcNAc), glucuronic acid (GlcA), galacturonic acid (GalA), N-acetylgalactosamine (GalNAc), glucose (Glc), galactose (Gal), xylose (Xyl), and fucose (Fuc), cetylpyridinium chloride (CPC), 1-phenyl-3-methyl-5-pyrazolone (PMP) and sodium borohydride $\left(\mathrm{NaBH}_{4}\right)$ were purchased from Sigma-Aldrich (St. Louis, MO, USA). The Eclipse XDB-C18 column $(4.6 \mathrm{~mm} \times 150 \mathrm{~mm}, 5 \mu \mathrm{m})$ was obtained from Agilent (Santa Clara, CA, USA), and Hypercarb KAPPA Capillary Column $(100 \mathrm{~mm} \times 0.5 \mathrm{~mm}, 3 \mu \mathrm{m})$ was obtained from Thermo Fisher Scientific 
(Waltham, MA, USA). Sodium hydroxide ( $\mathrm{NaOH}$ ), trifluoroacetic acid (TFA), $N$-acetylneuraminic acid (Neu5Ac), N-glycolylneuraminic acid (Neu5Gc), and 1,2-diamino-4,5-methylenedioxybenzene (DMB derivative) were purchased from Aladdin (Shanghai, China).

\subsection{Purification and Chemical Compositions of Rabbit Intestinal Mucin-Type Glycopeptides}

The hyla rabbit intestines mucosa were degreased by adding 20 volumes of chloroform/methanol (2:1) for $15 \mathrm{~h}$. The dried degreased mucosa powders were treated with papain, and the crude mucin-type glycopeptides were separated by cetylpyridinium chloride (CPC) precipitation. The nucleic acids that existed in the crude mucin-type glycopeptides were further removed by the isoelectric point precipitation method. The pure mucin-type glycopeptide (RIF6) was finally purified on a Q-Sepharose Fast Flow (QFF) column as previously described [48]. The purified fractions were dialyzed and lyophilized.

The monosaccharide composition was determined by using PMP labeling in conjunction with high-performance liquid chromatography (HPLC) as described by Chen et al. [49]. The sialic acid content was performed using a pre-column DMB derivatization as previous studies have reported [50].

\subsection{O-Linked Glycans Released from RIF6}

O-linked glycans were released from the hyla rabbit intestinal mucin-type glycopeptide by $\beta$-elimination. Briefly, the samples $(0.5 \mathrm{mg})$ were incubated with $50 \mathrm{mM} \mathrm{NaOH}$ and $0.5 \mathrm{M} \mathrm{NaBH}_{4}$ at $50{ }^{\circ} \mathrm{C}$ for $14 \mathrm{~h}$. Reactions were quenched with glacial acetic acid, 3 volumes of ethanol was added and then centrifuged, and the supernatants were dialyzed and freeze-dried.

\subsection{Analysis of O-glycans Released from RIF6 by Liquid Chromatography-Mass Spectrometry (LC-MS/MS)}

Herein, the LTQ-Orbitrap XL and Agilent 1260 capillary liquid systems were utilized for LC-MS/MS analysis. The $\mathrm{O}$-glycan samples were separated using a Hypercarb KAPPA column maintained at $25^{\circ} \mathrm{C}$. The mobile phase A consisted of acetonitrile and the mobile phase B consisted of $10 \mathrm{mM}$ ammonium bicarbonate. A loading volume of $0.2 \mu \mathrm{L}$ was utilized at a flow rate of $8 \mu \mathrm{L} \cdot \mathrm{min}^{-1}$ under the following gradient: $2 \%-8 \%$ A in $20 \mathrm{~min} ; 8 \%-15 \% \mathrm{~A}$ in $50 \mathrm{~min} ; 15 \%-35 \% \mathrm{~A}$ in $80 \mathrm{~min} ; 35 \%-60 \% \mathrm{~A}$ in $50 \mathrm{~min}$; and a final hold step from $60 \%-75 \% \mathrm{~A}$ in $5 \mathrm{~min}$. Electrospray ionization-mass spectrometry (ESI-MS) was performed in negative ion polarity mode with an electrospray voltage of $3 \mathrm{kV}$, a capillary voltage of $-41 \mathrm{~V}$, a lens voltage of $-120 \mathrm{~V}$, and a capillary temperature of $275^{\circ} \mathrm{C}$. The instrument was operated in Fourier transform (FT) mode with a sheath gas flow rate of $8 \mathrm{~L} \cdot \mathrm{min}^{-1}$ and a mass range of $280-3000 \mathrm{~m} / \mathrm{z}$. A full MS scan was performed first, followed by a data-dependent collision-induced dissociation (CID) MS/MS scan of the 5 most abundant ions. To obtain optimal fragmentation, the normalized collision energy was $30 \mathrm{~V}$.

\subsection{O-glycan Structural Annotation and Assignments}

The LC-MS/MS data was processed manually using Xcalibur (Thermo Fisher Scientific, Waltham, MA, USA) and GlycoWorkbench softwares (Alessio Ceroni et al., Imperial College, London, UK). Glycans were annotated manually based on their MS/MS spectra and then validated using available structures in the CarbBank database. The MS spectra and MS/MS spectra were analyzed using the Xcalibur software and the precise glycan structures were generated using GlycoWorkbench based on the different fracture fragments of the parent ions [51]. All of the quantitative data were calculated based on the integrated peak areas obtained from LC-MS chromatograms and formatted as a percentage $(\%)$ to represent relative quantitation.

Supplementary Materials: The following are available online. Table S1: Monosaccharide composition of four fractions purified on a QFF column, Table S2: O-glycan structures assigned by ESI-CID-MS/MS in RIF6 and comparison with other species, Figure S1: HPLC Chromatogram for sialic acid standards solution (Neu5Ac, Neu5Gc) and sample (RIF6), Figure S2: ESI-CID-MS/MS spectra of the remaining O-glycans from RIF6, Figure S3: Total ion chromatogram of assigned O-glycan structures of RIF6. 
Author Contributions: Conceptualization, G.L. and G.Y.; Data curation, Q.F., G.L., C.W. and G.Y.; Formal analysis, Q.F., C.W., Y.W. and Q.L.; Funding acquisition, G.L. and G.Y.; Investigation, Q.F., C.W., Y.W. and Q.L.; Methodology, Q.F., G.L. and G.Y.; Project administration, G.L. and G.Y.; Software, Q.F., Y.W. and J.H.; Supervision, G.L. and G.Y.; Validation, Q.F., G.L. and Q.L.; Writing—original draft, Q.F. and G.L.; Writing—review \& editing, G.L., J.H. and G.Y.

Funding: This research was funded by This work was supported by Grants from National Natural Science Foundation of China (31600646), the Fundamental Research Funds for the Central Universities (201762002), NSFC-Shandong Joint Fund for Marine Science Research Centers (U1606403), National Science and Technology Major Project for Significant New Drugs Development (2018ZX09735004) and Taishan scholar project special funds (TS201511011).

Conflicts of Interest: The authors declare no conflict of interest.

\section{References}

1. Mccracken, V.J.; Lorenz, R.G. The gastrointestinal ecosystem: A precarious alliance among epithelium, immunity and microbiota. Cell. Microbiol. 2001, 3, 1-11. [CrossRef]

2. Gum, J.R., Jr.; Hicks, J.W.; Gillespie, A.; Carlson, E.J.; Kömüves, L.; Karnik, S.; Hong, J.C.; Epstein, C.J.; Kim, Y.S. Goblet cell-specific expression mediated by the MUC2 mucin gene promoter in the intestine of transgenic mice. Am. J. Physiol.-Gastrointest. Liver Physiol. 1999, 276, G666-G676. [CrossRef]

3. Linden, S.K.; Sutton, P.; Karlsson, N.G.; Korolik, V.; Mcguckin, M.A. Mucins in the mucosal barrier to infection. Mucosal Immunol. 2008, 1, 183. [CrossRef]

4. Brockhausen, I. Pathways of O-glycan biosynthesis in cancer cells. Biochim. Biophys. Acta 1999, 1473, 67-95. [CrossRef]

5. An, H.J.; Ninonuevo, M.; Aguilan, J.; Liu, H.; Lebrilla, C.B.; Alvarenga, L.S.; Mannis, M.J. Glycomics analyses of tear fluid for the diagnostic detection of ocular rosacea. J. Proteome Res. 2005, 4, 1981-1987. [CrossRef] [PubMed]

6. Furr, A.E.; Ranganathan, S.; Finn, O.J. Aberrant expression of MUC1 mucin in pediatric inflammatory bowel disease. Pediatr. Dev. Pathol. 2010, 13, 24-31. [CrossRef]

7. Kirkham, S.; Kolsum, U.; Rousseau, K.; Singh, D.; Vestbo, J.; Thornton, D.J. MUC5B Is the Major Mucin in the Gel Phase of Sputum in Chronic Obstructive Pulmonary Disease. Am. J. Respir. Crit. Care 2008, 178, 1033-1039. [CrossRef] [PubMed]

8. Royle, L.; Matthews, E.; Corfield, A.; Berry, M.; Rudd, P.M.; Dwek, R.A.; Carrington, S.D. Glycan structures of ocular surface mucins in man, rabbit and dog display species differences. Glycoconj. J. 2008, 25, 763. [CrossRef] [PubMed]

9. Seipert, R.R.; Barboza, M.; Niñonuevo, M.R.; Locascio, R.G.; Mills, D.A.; Freeman, S.L.; German, J.B.; Lebrilla, C.B. Analysis and quantitation of fructooligosaccharides using matrix-assisted laser desorption/ionization Fourier transform ion cyclotron resonance mass spectrometry. Anal. Chem. 2008, 80, 159-165. [CrossRef]

10. Xia, B.; Royall, J.A.; Damera, G.; Sachdev, G.P.; Cummings, R.D. Altered O-glycosylation and sulfation of airway mucins associated with cystic fibrosis. Glycobiology 2005, 15, 747-775. [CrossRef]

11. Smith, R.F.; Stern, B.H.; Smith, A.A. Mucin immunohistochemistry in the diagnosis and mapping of extramammary Paget's disease. J. Cell. Mol. Med. 2008, 12, 1605-1610. [CrossRef]

12. Koropatkin, N.M.; Cameron, E.A.; Martens, E.C. How glycan metabolism shapes the human gut microbiota. Nat. Rev. Microbiol. 2012, 10, 323-335. [CrossRef]

13. Pacheco, A.R.; Curtis, M.M.; Ritchie, J.M.; Munera, D.; Waldor, M.K.; Moreira, C.G.; Sperandio, V. Fucose sensing regulates bacterial intestinal colonization. Nature 2012, 492, 113-117. [CrossRef]

14. Carabaño, R.; Badiola, I.; Chamorro, S.; García, J.; García-Ruiz, A.I.; García-Rebollar, P.; Gómez-Conde, M.S.; Gutiérrez, I.; Nicodemus, N.; Villamide, M.J.; et al. New trends in rabbit feeding: Influence of nutrition on intestinal health. A Review. Span. J. Agric. Res. 2008, 6, 15. [CrossRef]

15. Tailford, L.E.; Crost, E.H.; Kavanaugh, D.; Juge, N. Mucin glycan foraging in the human gut microbiome. Front. Genet. 2015, 6, 81. [CrossRef]

16. Karlsson, N.G.; Schulz, B.L.; Packer, N.H. Structural determination of neutral O-linked oligosaccharide alditols by negative ion LC-electrospray-MSn. J. Am. Soc. Mass Spectr. 2004, 15, 659-672. [CrossRef] 
17. Karlsson, N.G.; Karlsson, H.; Hansson, G.C. Sulphated mucin oligosaccharides from porcine small intestine analysed by four-sector tandem mass spectrometry. J. Mass Spectrom. 1996, 31, 560-572. [CrossRef]

18. Everest-Dass, A.V.; Abrahams, J.L.; Kolarich, D.; Packer, N.H.; Campbell, M.P. Structural Feature Ions for Distinguishing N- and O-Linked Glycan Isomers by LC-ESI-IT MS/MS. J. Am. Soc. Mass Spectr. 2013, 24, 895-906. [CrossRef]

19. Robbe, C.; Capon, C.; Coddeville, B.; Michalski, J.C. Structural diversity and specific distribution of O-glycans in normal human mucins along the intestinal tract. Biochem. J. 2004, 384, 307-316. [CrossRef]

20. Robbe, C.; Capon, C.; Coddeville, B.; Michalski, J. Diagnostic ions for the rapid analysis by nano-electrospray ionization quadrupole time-of-flight mass spectrometry of O-glycans from human mucins. Rapid Commun. Mass Spectrom. 2004, 18, 412-420. [CrossRef]

21. Thomsson, K.A.; Karlsson, H.; Hansson, G.C. Sequencing of Sulfated Oligosaccharides from Mucins by Liquid Chromatography and Electrospray Ionization Tandem Mass Spectrometry. Anal. Chem. 2000, 72, 4543-4549. [CrossRef]

22. Domon, B.; Costello, C.E. A systematic nomenclature for carbohydrate fragmentations in FAB-MS/MS spectra of glycoconjugates. Glycoconj. J. 1988, 5, 397-409. [CrossRef]

23. Robbe, C.; Michalski, J.; Capon, C. Structural determination of O-glycans by tandem mass spectrometry. In Glycobiology Protocols; Springer: Berlin, Germany, 2006; pp. 109-123.

24. An, G.; Wei, B.; Xia, B.; Mcdaniel, J.M.; Ju, T.; Cummings, R.D.; Braun, J.; Xia, L. Increased susceptibility to colitis and colorectal tumors in mice lacking core 3-derived O-glycans. J. Exp. Med. 2007, 204, 1417-1429. [CrossRef]

25. Struwe, W.B.; Gough, R.; Gallagher, M.E.; Kenny, D.T.; Carrington, S.D.; Karlsson, N.G.; Rudd, P.M. Identification of O-glycan structures from chicken intestinal mucins provides insight into Campylobactor jejuni pathogenicity. Mol. Cell. Proteom. 2015, 14, 1464-1477. [CrossRef]

26. Venkatakrishnan, V.; Quintana-Hayashi, M.P.; Mahu, M.; Haesebrouck, F.; Pasmans, F.; Lindén, S.K. Brachyspira hyodysenteriae Infection Regulates Mucin Glycosylation Synthesis Inducing an Increased Expression of Core-2 O-Glycans in Porcine Colon. J. Proteome Res. 2017, 16, 1728-1742. [CrossRef]

27. Holmén Larsson, J.M.; Thomsson, K.A.; Rodríguez-Piñeiro, A.M.; Karlsson, H.; Hansson, G.C. Studies of mucus in mouse stomach, small intestine, and colon. III. Gastrointestinal Muc5ac and Muc2 mucin O-glycan patterns reveal a regiospecific distribution. Am. J. Physiol.-Gastrointest. Liver Physiol. 2013, 305, G357-G363. [CrossRef]

28. Jin, C.; Padra, J.T.; Sundell, K.; Sundh, H.; Karlsson, N.G.; Lindén, S.K. Atlantic Salmon Carries a Range of Novel O-Glycan Structures Differentially Localized on Skin and Intestinal Mucins. J. Proteome Res. 2015, 14, 3239-3251. [CrossRef]

29. Robinson, L.S.; Lewis, W.G.; Lewis, A.L. The sialate O-acetylesterase EstA from gut Bacteroidetes species enables sialidase-mediated cross-species foraging of 9-O-acetylated sialoglycans. J. Biol. Chem. 2017, 292, 11861-11872. [CrossRef]

30. Varki, A. Loss of N-glycolylneuraminic acid in humans: Mechanisms, consequences, and implications for hominid evolution. Am. J. Phys. Anthropol. 2001, 116, 54-69. [CrossRef]

31. Suzuki, Y.; Ito, T.; Suzuki, T.; Holland, R.E.; Chambers, T.M.; Kiso, M.; Ishida, H.; Kawaoka, Y. Sialic acid species as a determinant of the host range of influenza A viruses. J. Virol. 2000, 74, 11825-11831. [CrossRef]

32. Ito, T.; Suzuki, Y.; Suzuki, T.; Takada, A.; Horimoto, T.; Wells, K.; Kida, H.; Otsuki, K.; Kiso, M.; Ishida, H. Recognition of N-glycolylneuraminic acid linked to galactose by the $\alpha 2,3$ linkage is associated with intestinal replication of influenza A virus in ducks. J. Virol. 2000, 74, 9300-9305. [CrossRef]

33. Karlsson, N.G.; Olson, F.J.; Jovall, P.A.; Andersch, Y.; Enerback, L.; Hansson, G.C. Identification of transient glycosylation alterations of sialylated mucin oligosaccharides during infection by the rat intestinal parasite Nippostrongylus brasiliensis. Biochem. J. 2000, 350 Pt 3, 805-814. [CrossRef]

34. Malykh, Y.N.; Schauer, R.; Shaw, L. N-Glycolylneuraminic acid in human tumours. Biochimie 2001, 83, 623-634. [CrossRef]

35. Schauer, R.; Srinivasan, G.V.; Coddeville, B.; Zanetta, J.P.; Guérardel, Y. Low incidence of N-glycolylneuraminic acid in birds and reptiles and its absence in the platypus. Carbohydr. Res. 2009, 344, 1494-1500. [CrossRef]

36. Schauer, R. Sialic acids: Fascinating sugars in higher animals and man. Zoology 2004, 107, 49-64. [CrossRef] 
37. Padler-Karavani, V.; Yu, H.; Cao, H.; Chokhawala, H.; Karp, F.; Varki, N.; Chen, X.; Varki, A. Diversity in specificity, abundance, and composition of anti-Neu5Gc antibodies in normal humans: Potential implications for disease. Glycobiology 2008, 18, 818-830. [CrossRef]

38. Mawhinney, T.P.; Adelstein, E.; Gayer, D.A.; Landrum, D.C.; Barbero, G.J. Structural analysis of monosulfated side-chain oligosaccharides isolated from human tracheobronchial mucous glycoproteins. Carbohydr. Res. 1992, 223, 187-207. [CrossRef]

39. Thomsson, K.A.; Holmén-Larsson, J.M.; ångström, J.; Johansson, M.E.; Xia, L.; Hansson, G.C. Detailed O-glycomics of the Muc2 mucin from colon of wild-type, core 1- and core 3-transferase-deficient mice highlights differences compared with human MUC2. Glycobiology 2012, 22, 1128-1139. [CrossRef]

40. Brockhausen, I. Sulphotransferases acting on mucin-type oligosaccharides. Biochem. Soc. Trans. 2003, 318-325. [CrossRef]

41. Tobisawa, Y.; Imai, Y.; Fukuda, M.; Kawashima, H. Sulfation of colonic mucins by N-acetylglucosamine 6-O-sulfotransferase-2 and its protective function in experimental colitis in mice. J. Biol. Chem. 2010, 285, 6750-6760. [CrossRef]

42. Uchimura, K.; El-Fasakhany, F.M.; Hori, M.; Hemmerich, S.; Blink, S.E.; Kansas, G.S.; Kanamori, A.; Kumamoto, K.; Kannagi, R.; Muramatsu, T. Specificities of N-Acetylglucosamine-6-O-sulfotransferases in Relation to L-selectin Ligand Synthesis and Tumor-associated Enzyme Expression. J. Biol. Chem. 2002, 277, 3979-3984. [CrossRef]

43. Berry, M.; Harris, A.; Lumb, R.; Powell, K. Commensal ocular bacteria degrade mucins. Br. J. Ophthalmol. 2002, 86, 1412-1416. [CrossRef]

44. Derrien, M.; van Passel, M.W.; van de Bovenkamp, J.H.; Schipper, R.G.; de Vos, W.M.; Dekker, J. Mucin-bacterial interactions in the human oral cavity and digestive tract. Gut Microbes 2010, 1, 254-268. [CrossRef]

45. Janssen, R.; Krogfelt, K.A.; Cawthraw, S.A.; van Pelt, W.; Wagenaar, J.A.; Owen, R.J. Host-Pathogen Interactions in Campylobacter Infections: The Host Perspective. Clin. Microbiol. Rev. 2008, 21, 505-518. [CrossRef]

46. Young, K.T.; Davis, L.M.; Dirita, V.J. Campylobacter jejuni: Molecular biology and pathogenesis. Nat. Rev. Microbiol. 2007, 5, 665-679. [CrossRef]

47. Naughton, J.A.; Mariño, K.; Dolan, B.; Reid, C.; Gough, R.; Gallagher, M.E.; Kilcoyne, M.; Gerlach, J.Q.; Joshi, L.; Rudd, P.; et al. Divergent Mechanisms of Interaction of Helicobacter pylori and Campylobacter jejuni with Mucus and Mucins. Infect. Immun. 2013, 81, 2838-2850. [CrossRef]

48. Chen, S.; Xue, C.; Yin, L.A.; Tang, Q.; Yu, G.; Chai, W. Comparison of structures and anticoagulant activities of fucosylated chondroitin sulfates from different sea cucumbers. Carbohydr. Polym. 2011, 83, 688-696. [CrossRef]

49. Chen, S.; Xu, J.; Xue, C.; Dong, P.; Sheng, W.; Yu, G.; Chai, W. Sequence determination of a non-sulfated glycosaminoglycan-like polysaccharide from melanin-free ink of the squid Ommastrephes bartrami by negative-ion electrospray tandem mass spectrometry and NMR spectroscopy. Glycoconj. J. 2008, 25, 481-492. [CrossRef]

50. Stanton, P.G.; Shen, Z.; Kecorius, E.A.; Burgon, P.G.; Robertson, D.M.; Hearn, M.T.W. Application of a sensitive HPLC-based fluorometric assay to determine the sialic acid content of human gonadotropin isoforms. J. Biochem. Biophys. Methods 1995, 30, 37-48. [CrossRef]

51. Ceroni, A.; Maass, K.; Geyer, H.; Geyer, R.; Dell, A.; Haslam, S.M. GlycoWorkbench: A Tool for the Computer-Assisted Annotation of Mass Spectra of Glycans. J. Proteome Res. 2008, 7, 1650-1659. [CrossRef]

Sample Availability: Not Available. 